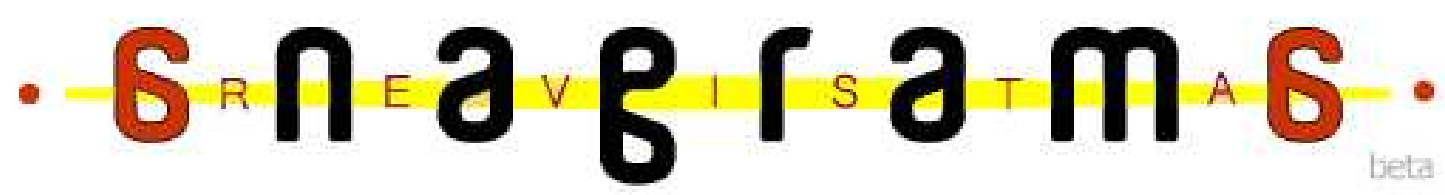

\section{Pode Chamar de G: notas sobre um projeto editorial}

Antonio Fernando Barros de Carualho ${ }^{7}$

\section{Resumo}

Toda revista possui um projeto editorial que serve como diretriz e ponto de acesso ao seu público-leitor. É este projeto que determina as abordagens realizadas pelo veículo, os temas pautados e as suas intenções. O presente artigo destaca alguns aspectos da proposta editorial da revista $G$ Magazine, voltada para o público homossexual masculino. Seu posicionamento se dá por meio de duas vias principais: a aproximação buscada a todo tempo com o leitor e os ensaios de nudez que festejam a intimidade sexual como uma forma de espetacularização.

Palauras-chaue: G Magazine; Projeto Editorial; Público-leitor.

\section{Um pouco de história}

Em 1997, sob o comando da jornalista Ana Fadigas e voltada para o público homossexual masculino, surge a revista $G$ Magazine, popularmente conhecida como $G$. Trazendo conteúdos jornalísticos associados a ensaios de nudez masculina, a publicação encontrou certa resistência para se posicionar no mercado. Num primeiro momento, faltavam jornalistas que pudessem assinar os conteúdos publicados, pois a grande maioria não queria vincular seu nome à revista, colaborando através de pseudônimos. As bancas também relutaram em aceitar vender G Magazine, o que forçou uma rota de distribuição alternativa: ela era repassada a saunas, boates, bares e espaços com nítida freqüência gay para, então, ser vendida.

Demorou tempo até $G$ Magazine despontar no mercado, o que ocorreu gradativamente. Surgiram os primeiros anunciantes, as bancas passaram a vendê-la e militantes do movimento gay na década de 1990 tornaram-se seus colaboradores como o

\footnotetext{
${ }^{1}$ Graduado em Comunicação Social com habilitação em Relações Públicas pela UNEB - Universidade do Estado da Bahia. E-mail: fernandobarros1988@ hotmail.com
} 
escritor João Silvério Trevisan, a transformista Nany People e o jornalista André Fisher. A publicação tomou forma e estruturou-se uma equipe de produção. A tiragem cresceu e $G$ Magazine conquistou um firme espaço de vendas em bancas e, posteriormente, de assinaturas. Hoje, possui circulação nacional.

A G Magazine se tornou conhecida do grande público devido à adoção de uma estratégia semelhante à da revista Playboy (voltada para homens heterossexuais): convidar pessoas famosas para posarem sem roupa e estampá-las em sua capa. Além das fotos de nu frontal, a revista, ao longo de sua trajetória, trouxe informações sobre comportamento, lazer e cultura além de entrevistas, colunas de aconselhamento e artigos sobre assuntos considerados de interesse homossexual.

Em 2008, G Magazine mudou sua orientação editorial. Comprada em nome do grupo norte-americano Ultra Friends, a revista sofreu um reposicionamento, que a tornou mais sexualizada, com mudanças em seu formato de publicação e na sua equipe de produção. O seu espaço editorial teve uma perda significativa: seções durante anos veiculadas foram suprimidas assim como outras tiveram sua extensão reduzida. Algumas colunas mudaram de nome e as matérias de comportamento bem como os textos de cunho reflexivo deram lugar a matérias sobre moda, beleza e entretenimento. A quantidade de ensaios de nudez duplicou, tornando o apelo sexual mais evidente.

Tal reposicionamento além de fruto da mudança de donos da revista pode ter se afigurado também como uma maneira de fazer frente a um mercado editorial gay mais fortalecido, uma forma de marcar a diferença em relação a outras propostas editoriais voltadas para o público homossexual, uma vez que desde 2007 surgiram outros importantes títulos no mercado, como as revistas Junior e Aimé. Assim, apostar no aumento de imagens de homens nus parece ter sido um caminho mais fácil para conquistar a atenção do segmento.

G Magazine é editada em 82 páginas pela Fractal Edições. A equipe responsável pela revista é aparentemente enxuta quando comparada a outros títulos brasileiros. Poucos nomes compõem o seu expediente. A redação é formada predominantemente pelos editores Marcos Brandão (chefe), Gustavo Ranieri, Rodrigo de Araújo e Fabiano Spadari (arte). A lista de colaboradores, pessoas que assinam conteúdos na revista, mas não necessariamente integram a redação, não ultrapassa 20 nomes. Entre esse, figuram, por exemplo, João Silvério Trevisan e o promoter carioca David Brazil. 
A publicação apresenta ainda uma equipe que fica à frente da produção dos ensaios ofertados a cada edição. É este núcleo quem contrata os modelos para posarem nus, idealiza e cuida de todos os preparativos para os ensaios, acompanha a realização das fotos etc. Há também os fotógrafos, parte importante dessa equipe, uma vez que as fotos de nudez publicadas representam o principal componente de G Magazine.

Em seu atual projeto, a revista pode ser sumarizada da seguinte forma: Recado do editor, seção de cartas, Mundo G, coluna Olho no Olho, coluna Voz ABGLT, coluna de David Brazil, seção Estilo, seção Beleza, Ensaio de Capa, Seção Arrasa!, Lolitos G (ensaio), Entrevista, Desejo (ensaio), G Travel, Dicas G Travel, $O$ melhor do $G$ on line (ensaio), G Recomenda, coluna SOS e coluna Fechação. Intercalando esses conteúdos, há uma imensa quantidade de páginas publicitárias. Em sua maioria, os anunciantes de $G$ Magazine são empresas e profissionais que prestam serviços voltados às necessidades do segmento gay. São marcas com pouca expressão nacional, a maioria com atuação no Sudeste do país, principalmente São Paulo, como centros de estética, casas noturnas, saunas, sites de relacionamento, casas de massagem, bares e restaurantes, lojas de decoração, videolocadoras, pousadas, motéis, lojas de roupas, preservativos, lojas de perucas e salas de cinema voltadas para o público gay. Em menor grau, aparecem escritórios de advocacia especializados em causas homossexuais, sexy-shops, marcas de perfumes, pontos de tatuagem, marca de colchão, clínicas veterinárias e dedetizadoras.

Marcas de grande notoriedade não costumam anunciar em G Magazine, mesmo, muitas vezes, tendo parte de seus respectivos públicos composta por homossexuais. A esse respeito, a pesquisadora Adriana Nunan (2003) fornece alguns indícios.

Quanto mais conteúdo sexual tiver uma publicação gay, menos anúncios ela veiculará. Curioso notar, no entanto, que isto se refere apenas às publicações com conteúdo sexual homossexual, pois revistas com fotos de mulheres nuas (como a Playboy) são recheadas de anúncios. A preocupação das empresas parece ser mais com a sexualidade homossexual do que com a sexualidade em geral (NUNAN, 2003: 186-187).

Existiria assim um argumento provável pelo qual anunciantes de maior expressão não figuram nas páginas publicitárias da G Magazine: Somado ao fato de a revista possuir fotos de nudez explícita, o enfoque da sexualidade homossexual numa sociedade ainda não totalmente afeita a formas distintas de experimentação da afetividade provocaria certa resistência das empresas em vincularem seu nome à publicação. A dificuldade na obtenção de anunciantes, por sua vez, representa um desafio, visto que os anúncios contribuem em 
grande medida para a sobrevivência dos veículos midiáticos no país, sendo grande parte de suas receitas advindas da venda de espaços publicitários. Não obstante este fato, $G$ Magazine tem conseguido atrair muitos anúncios, o que pode ser constatado pela expressão numérica com que eles aparecem na revista.

\section{De вау para вау}

Conhecidos brevemente a história da revista e o conteúdo que leva às bancas, interessa saber de que maneira ela põe em circulação seu projeto editorial. Que estratégias são utilizadas para materializar suas intenções e como se configura o modo de ser da publicação. Marília Scalzo, em seu estudo sobre revistas e o modo como se faz jornalismo dentro desse veículo de comunicação, salienta a importância da existência de uma proposta editorial. Segundo a autora, "uma boa revista começa com um bom plano editorial e uma missão definida - um guia que vai ajudá-la a posicionar-se objetivamente em relação ao leitor e ao mercado" (SCALZO, 2008: 61).

Desde seu nascimento até os dias atuais, G Magazine possui a característica de ser feita pelo gay para o gay e falando sobre assuntos de interesse gay. Ao representar o mundo à sua volta, agendar determinados assuntos e definir os conteúdos, a revista é produzida predominantemente por homossexuais. De forma resumida, ela procura se afirmar como uma abordagem gay pelo olhar gay, uma estratégia encontrada para alcançar o público ao qual se destina, no caso, homossexuais do sexo masculino. Esta seria a chave de sua proposta editorial. O fato de as equipes de redação e produção da $G$ serem compostas por homossexuais assumidos funciona como uma espécie de licença para o projeto discursivo posto em circulação pela revista. Em suas páginas, quem fala sobre conhece o que fala por que em última instância também pertence ao grupo de que se fala (DEZERTO, 2007).

Ao possuir uma equipe gay, G Magazine busca conquistar junto aos seus leitores legitimidade. Trata-se de uma forma de criar identificação e reconhecimento para aqueles que fariam parte da categoria homossexual. Nas páginas da revista, esboça-se um discurso de gay para gay e enseja-se um conceito de "nós" com a finalidade de criar um ambiente familiar e próximo ao leitor. Marília Scalzo trata dessa questão. Para a autora, as revistas buscam entrar na intimidade de seus leitores, oferecendo informações que os ajudarão em seu cotidiano e estabelecendo uma relação mais próxima do que outros meios de comunicação. "Revista é também um encontro entre um editor e um leitor, um contato que 
se estabelece, um fio invisível que une um grupo de pessoas e, nesse sentido, ajuda a construir identidade, ou seja, cria identificações, dá sensação de pertencer a um determinado grupo" (SCALZO, 2008: 12).

G Magazine visa manter uma relação íntima com o seu leitor, criando uma sensação de diálogo ao longo dos textos publicados e procurando estabelecer uma cumplicidade, como se existisse entre a revista e seu público uma intimidade partilhada a cada edição. A intenção é que entre quem lê e quem produz a revista não haja distâncias. Isso pode ser bem observado no Recado do Editor, que é editado como uma espécie de bate-papo entre o editor-chefe da revista e os leitores. Sendo porta-voz da publicação e homossexual assumido, Marcos Brandão apresenta as novidades do mês e discorre também sobre assuntos referentes ao universo gay, visando alcançar uma empatia. Em muitas edições, toca rapidamente em questões caras aos homossexuais como militância, reivindicação por direitos civis e homofobia. Ele fala ao leitor de igual para igual como um amigo ou alguém que aconselha.

Neste sentido, G Magazine veicula informações que julga de interesse do homossexual e procura pôr em prática a ideia de representar aquilo que seria uma comunidade gay. Adriana Nunan nos ajuda a entender este conceito.

\footnotetext{
Uma comunidade gay não se limita às redes de amizade nem aos bares, boates, restaurantes e saunas. Ela é na verdade um conjunto de instituições (incluindo clubes sociais e políticos, publicações, grupos religiosos, centros comunitários) que representam um sentimento de valores compartilhados e uma vontade de afirmar uma identidade homossexual. Ao contrário de outros tipos de comunidade (principalmente aquelas organizadas em torno de raças, etnias ou religiões), a comunidade homossexual tem como sua unidade básica o indivíduo, não a família, o que significa que a pessoa escolhe participar dela. Do mesmo modo, não é necessário que o dia-a-dia do homossexual gire em torno da comunidade para que ocorra algum tipo de identificação com esta (NUNAN, 2003: 139/140)
}

A ideia de uma comunidade gay é bastante recorrente ao longo da revista, como pode ser observado em seções como Mundo $G$ e Entrevista. A primeira é editada como se fosse uma panorâmica sobre o que acontece no universo gay. O próprio nome da seção é bastante sugestivo. Editada em quatro páginas, no decorrer delas, é possível encontrar diversas notícias sobre o que circula na sociedade sobre a questão homossexual. Através da seção, $G$ magazine parece transmitir ao leitor um posicionamento de que está preocupada com o que acontece à sua volta e de que representa os seus interesses, algo bastante significativo numa cultura vigente ainda permeada por preconceitos no que diz respeito a formas distintas de orientação sexual e, portanto, não muito receptiva à homossexualidade. 
Nesse contexto, chama atenção o box Merece aplauso. Merece vaia, publicado no espaço. Tal conteúdo visa destacar iniciativas favoráveis ao segmento gay e criticar as contrárias. Seria uma forma de indicar aqueles que apóiam as conquistas dos homossexuais e os que de algum modo são desfavoráveis. A questão pode ser melhor compreendida com base em Goffman (1988). O autor, ao estudar a questão dos estigmas, trata de publicações dirigidas a grupos discriminados socialmente feitas por pessoas que compartilham dessa discriminação e menciona tal estratégia:

Frequentemente, as pessoas que têm um estigma particular patrocinam algum tipo de publicação que expressa sentimentos compartilhados, consolidando e estabilizando para o leitor a sensação da existência real de 'seu' grupo e sua vinculação a ele. Nestas publicações, a ideologia dos membros é formulada - suas queixas, suas aspirações, sua política. São citados os nomes de amigos e inimigos conhecidos do grupo, junto com informações que confirmam a bondade ou maldade dessas pessoas. (GOFFMAN, 1988: 34)

Desse modo, de acordo com o autor, as publicações voltadas para um grupo estigmatizado teriam a função de representar seus interesses, valores e experiências, evidenciando aqueles que simpatizam com o segmento assim como os que se opõem. Tais publicações poderiam servir ainda como uma experiência reorganizadora, fornecendo orientação a tais categorias estigmatizadas, como no caso dos homossexuais, daí o sentido de nós sempre presente nestes impressos.

Em Mundo $G$, cumprindo o papel abordado por Goffman, comumente, são congratuladas ações que dão visibilidade às questões de interesse homossexual como reconhecimento de uniões estáveis entre pessoas do mesmo sexo, aprovação de regulamentos e leis que assegurem direitos ao segmento gay, parecer favorável a homossexuais em casos na Justiça sobre situações de discriminação, entre outras. Entre os acontecimentos criticados, figuram casos de homofobia, proibições de casamento entre homossexuais ao redor do mundo, usos de expressões discriminatórias em relação aos gays nos meios de comunicação de massa etc.

Um sentido de "gay para gay" também pode ser observado na revista através dos personagens que aparecem em diversos espaços da publicação, como na seção Entrevista. Ao estampar celebridades homossexuais ou envolvidas com este universo, o espaço contribui para a proposta de identificação almejada pela revista. A seção fornece elementos para uma identificação do leitor com os assuntos retratados, uma vez que aborda questões importantes para o gay e como elas são encaradas por pessoas famosas desse segmento, na 
maior parte dos casos, homossexuais assumidos. Forja-se mais uma vez uma ideia de "nós", que alimenta o projeto editorial da revista. Geralmente, os entrevistados são retratados como referenciais pelas suas trajetórias e contribuições na luta contra a discriminação contra os homossexuais. Aparecem como bem sucedidos, inteligentes, visionários, bem resolvidos, enfim, entrevistados-modelo. A publicação provavelmente busca oferecer ao leitor a possibilidade de modelos identificatórios positivos.

\section{0 espetáculo de $G$}

O projeto editorial de $G$ Magazine se sustenta de modo preponderante na apreciação da nudez masculina, daí o privilégio que esta adquire ao ser oferecida em quatro ensaios e constituir o conteúdo central da revista. Os nus masculinos, sobretudo o da capa, constituem o foco dessa publicação. Ao exibir a nudez explícita de seus modelos, $G$ Magazine entra em consonância com a era do espetáculo que caracteriza a contemporaneidade. Guy Debord nos ajuda a problematizar esse ponto. Para este autor, a espetacularização contemporânea vai além da onipresença dos meios de comunicação de massa e suas representações na vida social. O espetáculo compreenderia uma era na qual a realidade torna-se imagens e as imagens tornam-se realidade. Afirma o teórico: "o espetáculo não é um conjunto de imagens, mas uma relação social entre pessoas, mediada por imagens" (DEBORD, 1997: 14). E acrescenta: "sob todas as suas formas particulares informação, propaganda, publicidade ou consumo direto de divertimentos -, o espetáculo constitui o modelo atual da vida dominante na sociedade" (idem).

A cada mês, G Magazine oferece ao leitor quatro ensaios de nus masculinos. Além do ensaio de capa, a revista publica outros secundários: Lolitos $G$, Desejo e O Melhor do G on line. Para além de um nu artístico, eles possuem um forte teor erótico-pornográfico. Os modelos da revista aparecem em nudez explícita, sendo fotografados em poses variadas, muitas delas remetendo ao ato sexual. Se é o direcionamento do desejo sexual que distingue um gay e um heterossexual, é em função desse mesmo desejo que o projeto de $G$ Magazine se desenvolve. A inclinação pelo mesmo sexo além de ser uma das bases definidoras, pelo menos genericamente, do que significa ser homossexual, é também o eixo em torno do qual a revista se alinha.

Em G Magazine, a nudez de seus modelos é o principal aspecto de venda utilizado. Tanto é que eles estampam a capa da publicação, são pomposamente anunciados no editorial e é em função deles que determinado número é lembrado. A revista faz do desejo 
homossexual uma peça importante do projeto que põe em circulação, caracterizando um fenômeno chamado por Maria Celeste Mira de sexualização.

Para esta autora, a sexualização vem dominando diversos tipos de publicações. Tomando como parâmetro, a revista masculina Playboy e a Nova, direcionada ao público feminino, e as relações que cada uma delas estabelece com os seus leitores, a autora estabelece uma distinção no consumo sexual de homens e mulheres. Enquanto eles teriam um interesse calcado na visualidade, gostando de ver imagens de nudez feminina, o que justificaria o apelo dos ensaios eróticos em Playboy, elas se interessariam em discutir sexo e sexualidade sob diferentes óticas, daí a predominância de matérias de comportamento, artigos sobre sexualidade e colunas de aconselhamento sexual e psicológico nas páginas de Nova (MIRA, 2001)

O nu masculino é a mais contundente linguagem que G Magazine utiliza em seu diálogo com o público-leitor. Os homens jovens, musculosos, belos, viris, potentes, cheios de energia que estampam as páginas da publicação em poses íntimas/sexuais instauram uma atmosfera de sensualidade e prazer nas páginas da revista e convidam o leitor a se deleitar, a curtir, a aproveitar os divertimentos da vida. Ou como afirma Gabriel Rodrigues: "G Magazine expõe corpos-signos a serem co(nsu)midos no imaginário do leitor" (RODRIGUES, 2007: 103). Para este autor, no perímetro dos ensaios de nudez estabelecese uma relação de cumplicidade entre o que se desnuda - o exibicionista - e aquele que o contempla, o voyeur, mediada pelas lentes do fotógrafo.

O modelo é apresentado de modo íntimo, sensual, sedutor. Seus gostos, hobbies, fantasias eróticas, planos pessoais e profissionais são destacados como um modo de informar o leitor sobre sua vida privada. A intimidade como espetáculo. Este fenômeno é o mesmo descrito por Marilena Chauí, para quem os códigos da vida pública passam a ser determinados e definidos pelos códigos da vida privada e tal transformação se deve à forte influência da mídia na contemporaneidade (CHAUÍ, 1993: 09). Segundo essa autora, os meios de comunicação de massa são palco da manifestação do poder das chamadas personalidades, que vêm a público exprimirem seus gostos, sensações, opiniões e versões sobre o mundo.

Os homens nus estampados em $G$ são as personalidades que com seus corpossignos celebram a sensualidade no universo da revista, mas também "vendem" um estilo de vida que se baseia num estado permanente de alegria e curtição. O espetáculo de $G$ Magazine é também o espetáculo de exacerbação, excitação e maximização das 
oportunidades de prazer. Os modelos fotografados são sempre apresentados como pessoas que aproveitam a vida ao máximo, freqüentam baladas, são cobiçados, admirados, jovens, bonitos, charmosos e populares. São eles os referenciais a serem seguidos pelos leitores. São eles os espelhos nos quais devem se inspirar rumo a uma vida prazerosa.

\section{Considerações finais}

Em sua busca para alcançar o leitor, G Magazine apresenta-se como um veículo representativo do público gay. Para tanto, aciona em suas páginas um sentido de "nós", cujo objetivo é transmitir ao leitor a sensação de que ali no espaço da revista ele está entre iguais, o que pode ser evidenciado pelo fato de sua equipe ser formada predominantemente por homossexuais e pela linguagem utilizada nos textos ao longo das seções e colunas que compõem a publicação. Pode chamar de $G$, pode se reconhecer, pode se identificar. São essas as máximas que parecem estar implicitamente dispostas pela revista em seu contato com os leitores.

O projeto editorial de G Magazine se estrutura a partir desse posicionamento: ser um lugar íntimo para o público-leitor. Há de se observar que nos limites da publicação existe uma dupla condição de intimidade: ela se estabelece tanto no sentido de a revista ser editada para configurar "um lugar entre iguais" como através dos ensaios publicados a cada edição. Nestes ensaios, o que está em jogo é também a intimidade: a intimidade do modelo que se desnuda, num primeiro momento, procurando estabelecer uma cumplicidade com o leitor através do olhar, mas também a intimidade buscada pela própria revista ao oferecer para consumo imaginário do leitor o seu objeto de desejo sem roupa, sexualmente estimulado, entregue.

G Magazine cumpre efetivamente o seu papel enquanto revista e o transcende: não somente entra na intimidade de seus leitores como também oferece uma pretensa intimidade para ser consumida através dos seus ensaios de nudez e que vai moldar um pretenso estilo de vida gay calcado no prazer. Sem roupa, com forte apelo sexual, fotografados de modo sedutor e apresentados como pessoas aptas a realizarem os desejos mais velados, os homens nus estampados a cada número da revista são um sintoma dessa pretensão íntima de $G$, que marca o seu projeto editorial. 


\section{Referências Bibliográficas}

CHAUÍ, Marilena. Simulacro e poder: Uma análise da mídia. São Paulo: Editora Perseu Abramo, 2006.

DEBORD, Guy. A sociedade do espetáculo. São Paulo: Contraponto, 1997.

DEZERTO, Felipe Barbosa. Discurso e Homossexualidade: a construção de formassujeito, Universidade Estadual do Rio de Janeiro, 2007.

GOFFMAN, Erving. Estigma: notas sobre a manipulação da identidade deteriorada. $4^{\mathrm{o}} \mathrm{ed}$. Rio de Janeiro: LTC, 1988.

MIRA, Maria Celeste. O leitor e a banca de revistas: a segmentação da cultura no século XX. São Paulo: Olho d’ Água, 2001.

NUNAN, Adriana. Homossexualidade: do preconceito aos padrões de consumo. Rio de Janeiro: Caravansarai, 2003.

SCALZO, Marília. Jornalismo de revista. $3^{\circ}$ ed. São Paulo: Contexto, 2008.

RIPARDO, Sérgio. G muda e terá mais sexo. Folha On Line. Disponível em: http://www1.folha.uol.com.br/folha/colunas/destaquesgls/ult10009u376680.shtml Acessado em: 20 de janeiro de 2010

RODRIGUES, Gabriel de O. Corpos em evidência: uma perspectiva sobre os ensaios fotográficos de G Magazine. Dissertação de Mestrado em Ciências da Comunicação, Escola de Comunicações e Artes, Universidade de São Paulo, São Paulo, 2007.

VENCESLAU, Pedro. O governo do PT sempre foi mais friendlly. Revista Imprensa, São Paulo, n. 230/dezembro de $2007 . \quad$ Disponível em: http://portalimprensa.uol.com.br/revista/edicao_mes.asp?idEdicao=6\&idMateriaRevista=7 2 Acessado em: 20 de janeiro de 2010. 